\title{
Sustainability in Economics
}

Andrew Mearman and Anthony Plumridge, University of the West of England, Bristol Published by the Economics Network, January 2012

Online version at http://www.economicsnetwork.ac.uk/handbook/sustainability/

1 Introduction 2

2 Getting started 3

2.1 What is sustainability? 3

2.2 Integrate or specialise? 6

3 Teaching sustainability in a standard module 8

4 Teaching a contending perspectives course on economics $\begin{array}{ll}\text { of the environment } & 15\end{array}$

$5 \quad$ Teaching an applied course on sustainability economics 19

6 Assessment 24

7 Software resources - used as a teaching and assessment tool 25

8 Case studies (in practice) $\quad 27$

$\begin{array}{ll}\text { References and resources } & 28\end{array}$ 


\section{Introduction}

This Handbook chapter addresses the challenge of incorporating sustainability into Economics curricula. There is considerable evidence that there is demand for sustainability education. According to Forum for the Futures Future Leaders Survey of UCAS applicants in 2007/8, students are very concerned about the future of the world and identify environmental crises as important. Around two thirds of students said they wanted more sustainability in their syllabus. They also thought $(42 \%$ in $2007 / 8)$ that learning about sustainability would help their future careers. Over three quarters think significant changes are necessary now regarding how the world operates/is organised (Forum for the Future, 2007, 2008).

In addition there is considerable evidence that employers regard training for sustainability to be crucial in graduates. Cade (2007) showed that employers and students were paying greater attention to ethical issues including sustainability but that universities were having trouble catching up. The Independent (2009) reported that students with sustainability skills are in demand. Forum for the Future (2010) has several publications on the business case for sustainability. Business in the Community (2008) shows evidence of demand from employers for sustainability skills. Businesses are increasingly aware and taking on the message that sustainability matters. Organisations such as the Ellen Macarthur Foundation have strong links with businesses such as B\&Q and Kingfisher Group, who appear to support the 'closed-loop economy' message. The City and Guilds (2008) identify a shortage of green skills that needs to be addressed. Further, the EU Council has formally adopted education for sustainable development (ESD) as a policy goal (Council of the European Union, 2010).

The challenge is considerable, but also interesting, even for those with no interest in sustainability. Why? As will become apparent, the task of placing this issue in the curriculum involves a range of choices for the programme designer; it also requires the teacher to take an inherently multi-faceted, complex and interdisciplinary concept and place it in a disciplinary context. In addition, it forces the tutor to be aware of the pedagogical issues that become acutely manifest: the engagement of the student, helping them through their inevitable confusion, and the achievement of resolving their problems.

However, there are several reasons for trying to meet these challenges, not least because overcoming them could be personally rather satisfying. Second, given the prominence of the topic, the student is likely to be initially at least enthusiastic and engaged with the topic. Third, given the contemporary context - of climate change, resource crunch, biodiversity loss, food delivery

TOP
"Use examples to illustrate
unfamiliar sustainability
concepts: make it personal
not abstract. For example,
ask students to consider
their own consumption
patterns. Ask them to
consider their university as a
system. Murray (2011) may be
a good resource."
challenges, and so on - dealing with sustainability is arguably important. Fourth, the students will gain tremendously: given the multi-faceted, complex nature of sustainability, students will develop depth of understanding, the ability to weigh up conflicting opinions and value systems and make decisions in the light of them, and develop systemic thinking skills. Your students will come out better educated at the end. 


\section{Getting started}

Teaching sustainability involves choices. All teaching does, of course, but given the relative novelty of the subject and the lack of established resource bases, say, compared with core microeconomic theory, there are fewer ready-made guides on how to design sustainability curricula and how to deliver them. That lack of pre-existing structure can be liberating, but also daunting. However, the choices are unavoidable. There are two main sets of choices to be made. One is whether to integrate sustainability across the curriculum (if it is possible within institutional constraints) or whether to create specialist niches within it. That choice is followed by others, about the depth of integration, and about the theoretical approaches considered. We shall return to those issues shortly. Before that, the tutor needs to consider what they understand by sustainability. This chapter is designed to help tutors make these choices.

\subsection{What is sustainability?}

A common sense definition of sustainability is that a thing can last. However, what is it that lasts? A firm, an economy, a society, a species, an ecosystem? And when it lasts, does it grow or improve, does it deteriorate, or none of these? In other words, is sustainable development possible? Is it possible to trade off one type of sustainability - say, ecological - against another - say, economic? Are human manufactured goods equivalent to those produced in the rest of nature? Given these questions (and others) it is perhaps not surprising that there are so many definitions of sustainability (see Box 1). Perhaps the dominant definition of sustainability is from the Brundtland Report:

Sustainable development is development that meets the needs of the present without
compromising the ability of future generations to meet their own needs (WCED, 1987: 54).

If this definition is reformulated as: 'Future generations should inherit a stock of resources such that they can enjoy a quality of life at least equal to that enjoyed by present generations', it then becomes apparent that economics has at its heart the study of processes and behaviours that are also of paramount importance to moving towards sustainability. However, some authors from a strong ecological perspective have expressed dissatisfaction with such definitions. They argue that the whole notion of sustainable development is flawed, as they argue that growth and sustainability are fundamentally incompatible. They even hold (although the Brundtland definition is not guilty in this regard) that sustainability is incompatible with what might be described as 'business as usual'. Others, such as Birkeland (2008) argue for positive development, in which for instance new buildings or eco-retrofitted buildings are carbon-negative (i.e. the carbon emissions used in their production and operation is less than that produced by them via plants, solar panels, etc.). Recently, from an ecological economics perspective, Jackson (2009) has also discussed resilience of economies (and communities) as being able to withstand external shocks, such as swings in the oil price. However, this notion is not a replacement for sustainability.

Introducing sustainability to students can be done in a number of ways. One approach might start from an ecological perspective, which sees natural cycles that support ecosystems as the implicit foundation of any discussion of sustainability. An overview of these natural systems is necessary as the basis for exploring the impacts of different economic systems and activities. A few natural cycles could be introduced in early lectures or virtual material. These might include 


\section{Box 1: Some views of sustainability}

Most views of sustainability are concerned with the resource stock left for future generations. There are two common classifications of resources - the Five Capitals model (see below) and the conventional traditional classification into natural, human and man-made resources. Most discussion of sustainability by economists is in terms of the familiar three-resource model.

\section{The Five Capitals}

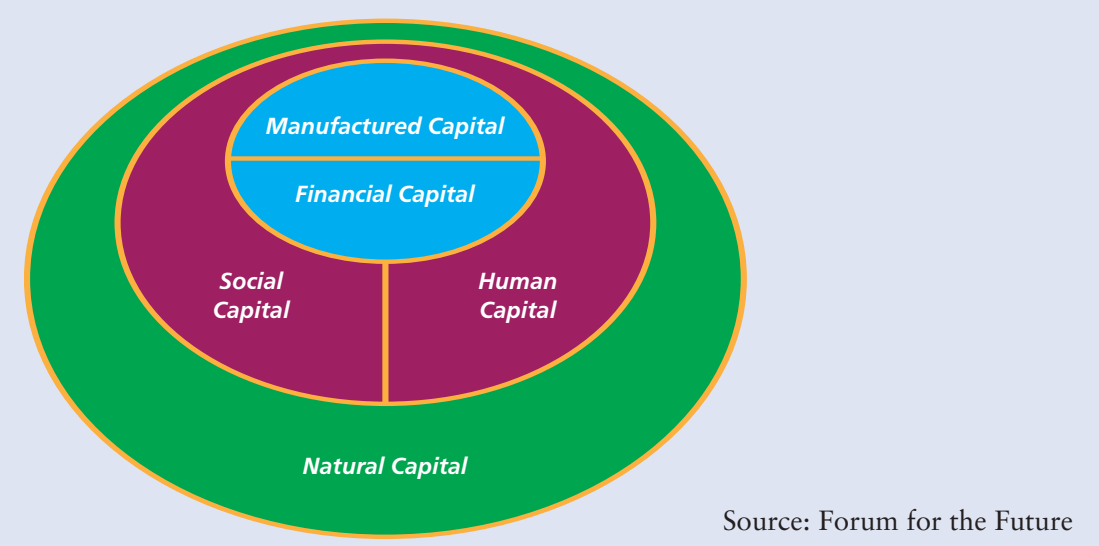

Much of the discussion of sustainability amongst economists is concerned with the relationship between economic activity and the natural environment. This reflects the existence of a large body of environmental economics research and literature and a less extensive oeuvre within ecological economics. It also reflects the urgency of issues surrounding climate change, resource depletion and pollution. It should be emphasised that any consideration of sustainable development should also discuss the conservation of all five capitals. Manufactured, financial and human capital are central to the conventional economics curriculum and not considered further here. Natural capital is the main focus below; however social capital should also be considered, albeit briefly, as it has escaped the attention of most economists. The concept of social capital originated in sociology (see, for example, Putnam, 2000) but has considerable currency in regional economics and is one of a multitude of diverse factors explaining differences in the performance of nations, regions and cities (Dasgupta, 2002). Social capital includes dimensions such as the strengths of institutions, behavioural tendencies towards collaboration, co-operation and mutual support, and strong community and interpersonal networks.

Various views of sustainability are discussed below, starting with the weakest formulation, in the sense that it imposes the least restriction on economic activity.

\section{Very weak sustainability}

The aggregate quantity of all resources is constant or increasing such that

$$
\Delta \mathrm{Kn}+\Delta \mathrm{Kp}+\Delta \mathrm{Kh} \geq 0
$$

Where there is substitutability between natural capital, $\mathrm{Kn}$, manmade capital, $\mathrm{Kp}$, and human capital, Kh. Under this view, Kn can be destroyed as a result of development providing one or both of $\mathrm{Kh}$ and $\mathrm{Kp}$ are increased to compensate. This represents a very limited view of the benefits that flow from the natural environment and incorporates little understanding of the life-supporting role of ecosystem services.

continued... 


\section{Weak sustainability}

Under this view, other resources remain substitutable for natural capital but keystone elements and processes are not substitutable. These are essential for the survival of ecosystems and must be protected. This position can be criticised on the grounds that it pays only grudging attention to the most obvious susceptible elements of ecosystems while accepting a general degradation and depletion of $\mathrm{Kn}$.

\section{Strong sustainability}

There is recognition of the lack of understanding of complex ecosystems. The approach introduces uncertainty and responds by adopting the precautionary principle and incorporating safe minimum standards. Under this perspective, the reduction in $\mathrm{Kn}$ is limited.

\section{Very strong sustainability}

Most ecological economists support definitions of sustainability that can be classed as very strong. An example is Herman Daly's four operating principles:

1 Renewable resources: the rate of harvest should be less than or equal to the population growth rate

2 Pollution: waste discharges should be below assimilative capacity and cumulative pollutants reduced to as close to zero as possible.

3 Non-renewables: the benefits from exploitation should be split between distributed profits and investment such that a renewable substitute is available at depletion

4 Macroeconomic controls: minimise physical material and energy throughput in the economy and control population growth

\section{The technological fix}

It is easy to stimulate discussion of views of sustainability around one or two issues of wide concern such as climate change, water resource shortages or marine acidification. A starting point might be to set students in groups to prepare an assessment of one or more of these problems to present to the class. Then, after each presentation, ask the class as a whole 'what can be done about it?' Usually a range of positions emerges ranging from 'no growth' through to 'science will find a solution'.

the carbon cycle, making connections with climate change; the hydro cycle, with a focus on areas of water shortage and the food chain, with discussion of the need for dietary changes if a growing population is to be supported. The advantage of exploring the ecological perspective

TOP

"Don't moralise. Admit that a great deal of the discussion around sustainability is value-driven and stress the importance of various different positions on it. " from the outset is that the concept of sustainability is readily understood. If this approach is followed, the concept can be introduced as the preservation and encouragement of these natural cycles and ecosystems to maintain or increase bio-diversity. Another approach is to introduce ecological systems when relevant to particular economic topics. However, this leads to a fragmented understanding of what is essentially an interrelated set of natural systems.

This might be heavy going for those students not particularly committed to sustainability and be perceived as 'preachy'. Also, for economists the material might be somewhat inaccessible. An alternative approach therefore is to start from more familiar precepts. The concept of the Triple Bottom Line (Elkington, 1997) may help here. The traditional notion of a bottom line is profitability. The Triple Bottom Line concept suggests that for sustainability, profitability must be married to ecological and social sustainability. Thus, profitability may need to be sacrificed (to some extent) in a trade-off with the other dimensions. Such trade-offs ought to be familiar to economics students. 
The Triple Bottom Line relates to another useful concept, the 'Five Capitals' approach to sustainability (see Goodwin, 2003) shown in Box 1. Definitions of the economic problem in introductory courses almost always introduce scarce resources as the defining context of an economic system. The conventional approach is to present the three major categories of resources: natural, human and man-made. To these, entrepreneurship, financial capital and technological knowledge may also be added. This is very close to the 'Five Capitals'. These are natural capital, human capital, manufactured capital, social capital and financial capital. The model is the basis of one definition of sustainable development. Goodwin suggests that for sustainability, the total stock of the five capitals should be maintained although the depletion of one type can be compensated for by the increase in others. For example, lost agricultural land (natural capital) could be replaced by a shopping centre (manufactured capital); or forests could be replaced by carbon capture and storage power stations. But, this substitutability is frowned upon by adherents to stronger views of sustainability. However, it should be noted that mainstream economics is concerned with the flow of resources into the economic system while the discourse of sustainability focuses on stocks and the rate of depletion or degradation.

It is important that students are exposed to (at least some of) these different definitions, in order to demonstrate that sustainability is a contested concept. That understanding ought to make it clearer to them why there is so much debate about sustainability. However, the tutor clearly cannot juggle all of these balls in the air at once and must make some choices about how they define sustainability in their approach. This choice is also crucial, because it will condition the extent to which they might wish to integrate sustainability into the curriculum, whether they take a more or less interdisciplinary approach, whether they consider (for instance) economic sustainability alone, and to what extent they wish to incorporate approaches to sustainability which lie somewhat outside the mainstream (for

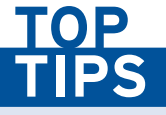

"Engage students in real problems; including discussing openly the global challenge of sustainability." example in ecological economics). Indeed, the definitions of sustainability help define the distinction between mainstream and ecological economics: the former favour very weak or weak sustainability, while the latter favour strong or very strong sustainability.

Further, if the tutor wishes to discuss sustainability in a broader sense (for instance via the Triple Bottom Line) they might use the different definitions as entry points into debates about policy, good business practice, etc. Some policy options (for example, some so-called 'technological fixes') would be ruled out if one took a strong sustainability approach.

\subsection{Integrate or specialise?}

If a tutor regards sustainability as of fundamental importance, they may wish to integrate it fully into the Economics curriculum. Whether they are able to will, of course, depend on institutional constraints and their own skills of negotiation. Those concerns are beyond the scope of this chapter. Given that one could integrate sustainability, there are different ways to do this. At one end of the spectrum, a programme might be designed according to problem-based learning (PBL) principles: the problem to be addressed would be achieving an economy that supports a sustainable world, and all the learning would be working towards a solution (see for example, Forsyth, 2010). PBL in its purest form allows the curriculum to unfold as the course progresses. That of course requires great skill on the part of the instructor. Witham and Mearman (2008) discuss some existing uses of PBL in ecological economics courses. That there are some examples of PBL in this area is perhaps not surprising, because sustainability lends itself to a PBL approach: clearly sustainability is a 'big', multi-faceted problem, meaning that the course could unfold in a multiplicity of ways. As discussed below (Assessment) one can design coursework assignments or exam tasks around specific problems.

If PBL is a step too far, a course could still begin with the problematic of a sustainable biosphere and then explore the implications of that for an economy via more conventional teaching. 
Alternatively, sustainability could still be the central theme (or one of a small number of themes) in a curriculum. Where appropriate, all modules would be organised with sustainability in mind. That would involve constructing examples, exercises and assessment that are all concerned with sustainability. Boxes 2 to 5 also discuss ways of delivering standard concepts such as the circular flow of income with added sustainability content. Such tools would be useful even if sustainability were not a central theme, but instead was a topic which needed to be included in all modules. This last form would be the weakest form of integration, in which sustainability is tacked on to a standard module, often at the end. Section 3 below discusses a standard introductory and one standard intermediate economics course into which examples and applications from sustainability are incorporated easily.

In the strongest forms of integration, students may learn all they need about sustainability simply by doing other modules. However, in those cases, and certainly in weaker forms of integration, students may have had their interest in sustainability stimulated and desire more specialised, detailed knowledge. So, even if a student has been on a programme that integrates thoroughly sustainability at level 1 (and/or 2), they might desire specialist modules at level 2 and/or 3. At this point, the choice for the tutor becomes one of which approaches to choose. Again, this may reflect their understanding of sustainability. Those who understand sustainability more narrowly may choose to deliver

"Don't try to shoe-horn in too much material. The course you create must remain coherent, and varied." sustainability solely according to mainstream principles, as found in standard treatments of environmental and/or natural resource economics. Those who take a broader view of sustainability may wish to deliver an ecological economics perspective. In this latter group, as indicated above, it may be possible to begin with a discussion of a sustainable biophysical ecosystem and derive the economics from it. A third alternative would be to try to deliver the two approaches in parallel or debate. Such an approach presents many challenges but may also yield many benefits (see for instance Mearman, 2007 on heterodox economics; and Mearman, et al., forthcoming, for a discussion of this).

The main body of the chapter examines in detail how these different alternatives could be delivered. Section 3 explores ways in which sustainability may be taught in standard economics modules. Sections 4 and 5 discuss different variants of specialist courses on the environment or sustainability: Section 4 discusses a course on economics of the environment, with sustainability emphasised, in which environmental and ecological economics perspectives are compared. Section 5 discusses a course in the economics of sustainability. 


\section{Teaching sustainability in a standard module}

The first available way to integrate sustainability into an economics curriculum is to simply tack it on as a subject at the end. However, in practice such topics tend to get dropped, or not included on exams. A more effective way to integrate sustainability - though requiring greater co-operation from staff - would be to use examples from sustainability. Table 1a outlines an introductory economics course, taking in microeconomics and macroeconomics, into which applications to sustainability have been added. The table presents possibilities for inclusion:

\begin{tabular}{|c|c|}
\hline Topic & Sustainability augmentation \\
\hline \multicolumn{2}{|l|}{ Microeconomics } \\
\hline Positive/normative distinction, etc. & Multiple ethical bases: triple bottom line (see Elkington, 1997) \\
\hline Scarcity; economic problem & Scarcity: absolute versus relative \\
\hline Markets: supply and demand & Carbon markets; oil market (could include 'peak oil') \\
\hline Demand theory; elasticity & Effect of a tax on petrol; road charging \\
\hline Theory of returns and costs & End-of-pipe technology and costs ${ }^{1}$ \\
\hline Theory of the firm & Increase of resource/raw material/energy costs \\
\hline $\begin{array}{l}\text { Market structures } \\
\text { yield (see Box 2) }\end{array}$ & Joint profit maximisation - fishing and maximum sustainable \\
\hline Market failure & Externalities of pollution \\
\hline Micro policy & Carbon rations, petrol taxes; optimal amount of pollution \\
\hline \multicolumn{2}{|l|}{ Macroeconomics } \\
\hline Circular flow of income & Circular flow extended to include biosphere (see Box 2) \\
\hline Macroeconomic objectives & Sustainability as an objective; an extra trade-off \\
\hline Economic growth & $\begin{array}{l}\text { Sustainable development; alternative measures of well-being, such } \\
\text { as Index of Sustainable Economic Welfare (ISEW), Happiness } \\
\text { indices, and the Happy Planet Index (HPI); environmental } \\
\text { Kuznets curve (see Box 7) }\end{array}$ \\
\hline Keynesian macroeconomics & Green stimulus packages (see New Economics Foundation, 2008) \\
\hline Unemployment & Green jobs \\
\hline Inflation & $\begin{array}{l}\text { Price of green products; finite resource cost inflation; backstop } \\
\text { technology (see Box } 8 \text { ) as a response to inflation }\end{array}$ \\
\hline Money demand and supply & $\begin{array}{l}\text { Green economics treatments of money as debt; carbon as a } \\
\text { currency; local currencies }\end{array}$ \\
\hline Monetary policy & Green quantitative easing \\
\hline Fiscal policy & Green stimulus packages; carbon and pollution taxes \\
\hline International trade & Transport costs; the Kyoto protocol; localism versus globalism \\
\hline Exchange rates & Carbon trading markets \\
\hline & ${ }^{1}$ End of pipe technology refers to adaptatons of existing plants to reduce pollution. \\
\hline
\end{tabular}


TOP

TIPS

"Utilise the extensive range

of software packages

available. See Section 7 for

some examples."

tutors can pick and choose topics depending on how deeply they wish to explore sustainability. The sustainability topics do have some logical progression, but they could be taught independently.

Some of the sustainability topics included are easy to include, whereas others require more ingenuity. Examples of the former are the discussion of the effect of a tax on petrol as an example of elasticity; the carbon market as a market to study; and the treatment of pollution externalities. On the macro side, the effect of natural resource costs on inflation, the use of fiscal policy for green stimulus, and the measurement of standards of living are also simple to introduce. In the category of more difficult topics would be those that require conceptual shifts, such as the discussion of multiple ethical bases, joint profit maximisation, and sustainability as an economic objective (see above; and see Box 2 below).

\section{Box 2: Renewable resources}

Theories of the exploitation of renewable resources are covered in most standard environmental economics texts covering natural resource economics. Students are interested (at least to some extent) in the escalating price of fish and chips and this represents a good context for discussing the management of fish stocks and behaviour of fishing enterprise under different regimes.

Information has an important role in the sustainable harvesting of renewable resources (see for example, Clark, 1990). If those exploiting the resource act in their mutual longterm self-interest and have full information about the impact of various levels of harvesting on stock levels, then the risk of over-exploitation is removed and the maintenance of carrying capacity is more likely. It is fascinating that traditional hunter-gatherer societies often had such information systems embedded in their cultures, reinforced by a system of beliefs and rituals.

The figure below shows the outcome of restricted access to a renewable resource, for example, where the number of operators is restricted through a licensing system.

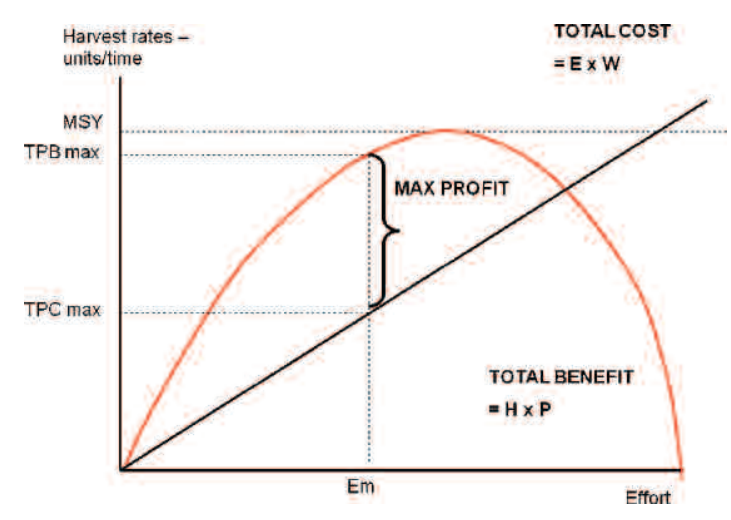

The figure above shows the outcome of joint profit maximisation where hunters or fishing enterprises act to limit their activity (effort) so that the maximum harvest relative to effort is achieved. As effort $(\mathrm{E})$ increases, the harvest rate $(\mathrm{H})$ initially increases but peaks at the maximum sustainable yield (MSY) where stock density and food supply allows the maximum rate of reproduction. Additional effort causes stocks and hence population density to fall and increasing difficulty in mating. Joint profit maximisation (at Em) requires barriers to entry and restriction on individual enterprise effort. Good information on fish stocks, catches, etc. will enhance stability. With open access, additional effort is made, stocks fall and the reproduction rate falls so that profit is zero.

In the diagram, $\mathrm{W}=$ wage rate, $\mathrm{P}=$ price per unit of catch, $\mathrm{TPB}=$ total private benefit, $\mathrm{TPC}$ $=$ total private cost. 
All would involve the commitment of some time by the tutor. Even more challenging (as hinted at by the discussion of multiple ethical bases) can be ventures into other disciplines. Examples are the extended circular flow of income (see Box 3 below), end-of-pipe technology and its effects on costs, green treatments of money (see Scott Cato, 2008: ch. 5), 'green' quantitative easing, and discussions of geological theories, such as peak oil. Whether or not and how these get taught will depend on how much time is available, the willingness of the tutor, and the availability of relevant supporting resources. As in Table $1 \mathrm{~b}$ below, the topics above can be delivered either as an entire suite, or more likely, selected to enrich a standard module, alongside examples from other relevant broad topic areas.

The extended circular flow model has a natural resource stock located at the centre and the flows of materials and services to and from the household and productive sectors indicated by arrows. An approach that has proved successful is to present the conventional circular flow in a lecture and ask where the natural environment and ecosystem services are. It is conventional for students to answer that these are contained within land. Ask the class for examples of the inputs that come from land. Usually students ignore the ability of the natural environment to provide waste assimilation services. They also ignore the waste assimilation and amenity services provided to households. That omission is the justification for making these ecosystem services explicit by adding to the diagram as above.

Clearly at the introductory level there is plenty of scope for examining sustainability issues. At the intermediate level, this is also true. In this case we shall discuss an intermediate microeconomics course with sustainability material included. One could of course also construct an intermediate macroeconomics course augmented for sustainability. The issues of integration, resourcing, specialist knowledge required and time constraints are present as in the case of the introductory course. In some respects they are even more acute because the technical level of the material is higher. In other respects, though, integration of sustainability is just as easy, if not easier. Table $1 \mathrm{~b}$ outlines an intermediate microeconomics course augmented for sustainability. As above, although it is possible to deliver all of these augmentations, that is not necessary. The suggested discussion topics can be inserted individually into a conventional course.

\section{Box 3: Extending the circular flow of income}

The circular flow of income is a foundational tool in economics, and is typically found in introductions to macroeconomics. The typical circular flow model presents flows of income, expenditure, goods and services between groups of economic actors. The version below is highly simplified, collapsing government and import sectors into 'businesses'.

\section{Product Market}

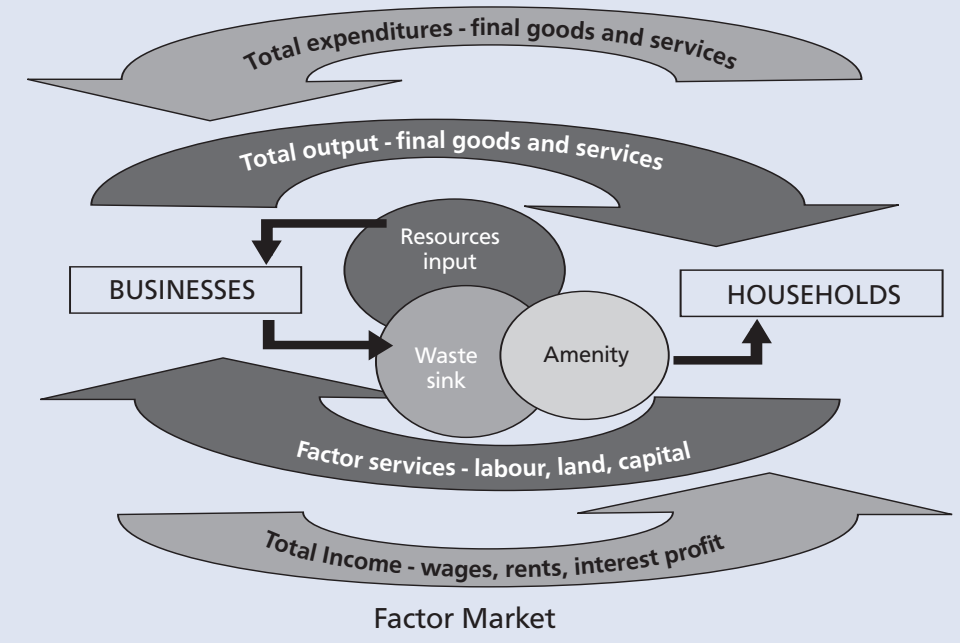




\begin{tabular}{|c|c|}
\hline Topic & Sustainability augmentation \\
\hline Consumer theory & $\begin{array}{l}\text { 'Economic man' vs. 'Eco-man' (see Becker, 2006); } \\
\text { willingness to pay (WTP), willingness to accept (WTA); cost } \\
\text { benefit analysis (CBA) }\end{array}$ \\
\hline $\begin{array}{l}\text { Analysis of choice under risk } \\
\text { and uncertainty }\end{array}$ & $\begin{array}{l}\text { Problem of non-probabilistic (Knightian) uncertainty? } \\
\text { Question the value of the expected utility hypothesis under } \\
\text { uncertainty }\end{array}$ \\
\hline $\begin{array}{l}\text { Analysis of investment appraisal and } \\
\text { long-term decision making }\end{array}$ & $\begin{array}{l}\text { Assumptions made? Discounting and the environment? } \\
\text { Precautionary principle }\end{array}$ \\
\hline Isoquant theory & $\begin{array}{l}\text { Questioning the nature of capital; natural capital; the shape } \\
\text { of isoquants }\end{array}$ \\
\hline Theories of the firm & Alternative goals: business ethics \\
\hline Labour markets & Basic income schemes \\
\hline Market structure and efficiency & OPEC and oil prices \\
\hline Game theory & $\begin{array}{l}\text { Climate change negotiations and compliance -see discussion } \\
\text { of classroom games. }\end{array}$ \\
\hline Price discrimination & Peak flow pricing \\
\hline General equilibrium analysis & Welfare effects of climate change \\
\hline Public goods and merit goods & Environmental impact evaluation \\
\hline Externalities and their internalisation & Pollution and its abatement \\
\hline
\end{tabular}

For example, once students have discussed consumer theory, it is an easy step to discuss the notion of an eco-man (cf. economic man) whose concerns with sustainability may override utility from consumption of some goods; or for whom preferences are lexicographic in favour of sustainably-produced goods. Also, indifference curve analysis can be used to discuss willingness to pay and willingness to accept (see for example, Perman et al., 2003: ch. 12). Notions of compensating and equivalent variations help illustrate cost benefit analysis. The topic of valuation is discussed further in Box 3, which also discusses cost benefit analysis; and the software package CBA Builder (Wheatley, 2010) is discussed in Section 7.

For some of the topics shown in Table $1 \mathrm{~b}$ the sustainability aspect is very clear: for example, general equilibrium, public and merit goods, and externalities are often taught anyway using environmental examples. For some of the other aspects it is also fairly trivial to introduce sustainability. For instance, OPEC is often used as a case study in oligopoly. The sustainability angle could be extended to discussing broader aspects of OPEC strategy, such as linking production to reserves. The theory of peak oil could be discussed at this point. Sustainability also lends itself to a discussion of price discrimination. An interesting exercise in price discrimination is to present students with apparent examples of it - such as fair trade

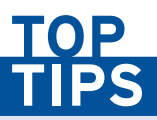

"CBA Builder, like any tool, takes practice to master. Ask students to perform multiple evaluations." versus other coffee, feed-in electricity tariffs, organic versus non-organic food - and discuss whether (and why not) these are true examples. Modelling climate change treaty negotiations and compliance could also be a good vehicle for teaching game theory. It is easy to use a simple Prisoner's Dilemma to discuss the likelihood that one country would renege on climate deals; and then discuss why this analysis might explain why climate deals are difficult to negotiate. It is also easy to incorporate discussions of sustainability into the topics of investment appraisal and long-term decision making. Clearly, as discussed in Box 3, discounting is a crucial feature of valuation of ecological objects, and of CBA. Some students may appreciate the chance to discuss concrete cases of a non-financial nature; others may wish to discuss what discount rates ought to be. Ackerman (2009) provides an illuminating discussion of discount rates from the 


\section{Box 4: Valuation}

Cost benefit analysis (CBA) is an ideal point at which to introduce the valuation of environmental assets. CBA has been criticised for failing to evaluate environmental impacts, merely describing them in physical units. Over the past 30 years, methodologies for evaluation in money terms have been evolving, although these are not widely used as they have proved expensive and unreliable. Nevertheless, it is often argued that it is better to have some monetary evaluation rather than a physical measure that is not included in the net present value and thus easy to ignore. The application of valuation techniques has been given a boost recently by attempts to evaluate ecosystem services and 'green infrastructure' by central and local government (see for example www.greeninfrastructure.org.uk).

\section{Total economic value of natural capital}

Discussing total economic value (TEV) with students as an introduction to evaluation encourages reflection on the meaning of value in economics. TEV is made up of use value and non-use values. Use value can be direct where, for example, a lake is used for fishing, or indirect, where it provides the setting for a pleasant walk. Non-use value is usually divided into a number of categories representing different ways in which a natural asset may bestow value:

- Option value arises from the retention of the asset for possible use in future, for example moorland which might be used for grazing or forestry in future.

- Quasi-option value is based on a possible use which may arise in future due to new knowledge about the asset. An example would be the Amazon Rain Forest where many plant species remain to be catalogued and some might yield a valuable drug for medical use.

- Existence value derives from an emotional attachment people feel for natural assets that acquire some cultural significance, even though there may never be an opportunity to experience the assets at first hand. Threatened species such as whales, rhinos and tigers evoke strong feelings as do iconic landscape features - Everest, the Danube, the Grand Canyon. Subsets of existence value include heritage value (the desire to preserve the asset for future generations) and vicarious use value (associated with contemplating the enjoyment of the asset by others).

\section{Evaluating environmental impact}

Most development incurs environmental costs as a result of the destruction or degradation of environmental assets or by causing pollution. For example, building a new road will interfere with natural drainage, cause pollution of watercourses, and act as a barrier severing wildlife habitats. It will result in noise and congestion to local communities in the construction phase. It will continue to have an impact on amenity by causing noise and pollution subsequently. In many cases, the impact will reduce the use value of the asset. Direct use may be associated with a marketed output and the reduction in this is the basis for evaluating impact. Indirect use may also be marketed where entrance fees are charged. Where there is no money transaction, there are three main methods of evaluation:

- Contingent valuation method (CVM) elicits values from a representative sample of an appropriate population by describing a context where an environmental asset is (usually) destroyed. Respondents are then asked how much they would be willing to pay (WTP) to preserve the asset or how much they would be prepared to accept in compensation (WTA) for the loss. Unique among valuation methods, CVM can capture all the components of TEV.

- Travel cost assumes that the expense of travelling to visit an environmental asset is a good proxy for a price for the benefits of the visit. By surveying a sample of visitors to 
the asset and collecting travel cost and other socioeconomic data, it is possible to generalise to the total population of visitors and construct a demand curve for the benefits flowing from the asset. The method only captures use value.

- Hedonic pricing uses the variation in the prices of dwellings or remuneration levels associated with different environmental conditions as a source of evidence of the WTA for tolerating those conditions. The most frequent application has been the variation in house prices with proximity to some nuisance (such as aircraft noise from an airport) or some environmental asset (such as a riverside location). Applying the technique requires the collection of house price data in the area, together with house and neighbourhood characteristics that might also have an influence on price. Econometric estimation of a house price function will allow the component of the price associated with the environmental attribute of interest. This is the basis for deriving a WTP or WTA associated with the attribute. Again, this method only captures use values.

\section{Benefit transfer}

As more studies of the values of environmental assets and conditions are completed, a database of valuations can be built up. Increasingly, it becomes possible to use the results of previous studies as the basis for valuation in new projects without having to carry out an asset valuation from scratch. The UK repository of valuations is available here.

\section{A critique of valuation methods}

Detailed descriptions of the methods briefly outlined above can be found in most standard texts on environmental economics. These usually include a listing of the shortcomings of the methodologies with more detail on operationalisation. Suffice it to say that, as the number of studies have built up, the range of values for similar assets has been disturbingly wide suggesting serious reliability issues.

\section{Introducing valuation to students}

This is a very rich area for exploring issues in applied economic methodologies and for discussing underlying theoretical issues. As an introductory exercise, groups of students can be asked to choose an environmental asset to value and then be given 15 minutes or so to sketch a valuation methodology they might apply. Each group then describes their methodology and this leads to some interesting discussion of problems and challenges.

viewpoint of sustainability. More difficult for economics tutors to discuss might be questions of the nature of capital (and therefore substitutability); and non-probabilistic uncertainty. Yet, uncertainty of this type is pervasive in sustainability questions. Sensitivity analysis can assist us in imagining future scenarios but it is instructive for students to consider what they would do when they simply do not know future risks.

CBA (see Box 5) is an excellent application for students to consider. It has clear policy implications and usefulness and deals with concrete examples. CBA is used in a variety of contexts within government. It also serves as an excellent pedagogical tool, as it can stimulate discussion about what and how to measure objects, whether or not they are amenable to measurement and, if not, how to deal with them. CBA Builder (Section 7) is a good tool for teaching and for students to master Excel. It is therefore useful on any applied microeconomics course. Further, attitudes to CBA are also one of the division points between environmental and ecological economists: the latter are sceptical of CBA and at best favour cost-effectiveness analysis. 


\section{Box 5: Cost benefit analysis (CBA)}

Investment appraisal (IA) is a good starting point for introducing CBA. This establishes the basic cash flow foundation, the distinction between one-off capital and recurring current expenditures and discounting. IA can be presented as capturing the private costs and benefits of a project. The introduction of external costs and benefits transforms IA into CBA.

Presenting a case study helps to emphasise the relevance of the subject. An example taken from a study of tourism development in Minorca is shown below:

\section{Private investment appraisal}

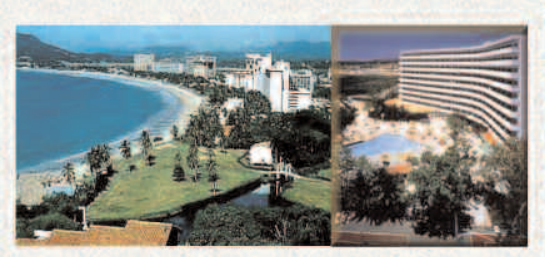

$$
\begin{aligned}
& \text { NPV }=£ 1.73 \mathrm{~m} \text { per } \\
& 1000
\end{aligned}
$$
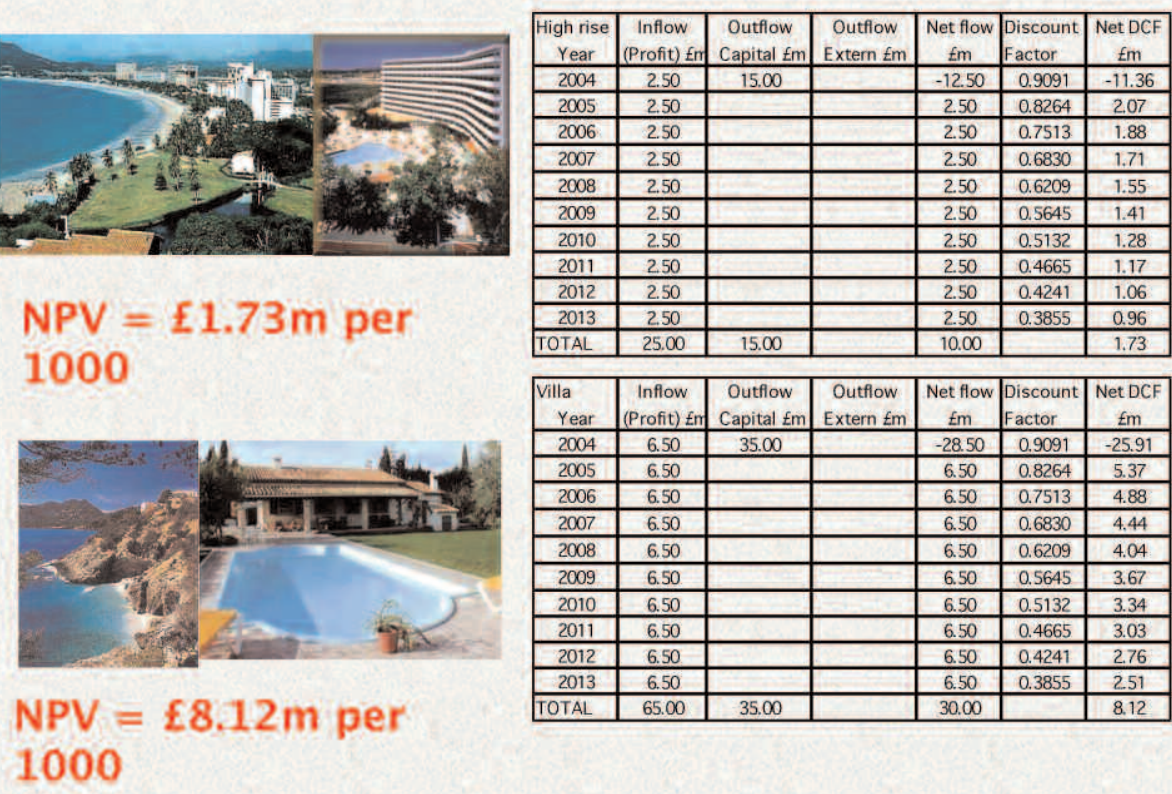

\begin{tabular}{|c|c|c|c|c|c|c|}
\hline $\begin{array}{c}\text { Villa } \\
\text { Year }\end{array}$ & $\begin{array}{c}\text { Inflow } \\
\text { (Profit) } \mathrm{fm}\end{array}$ & $\begin{array}{c}\text { Outflow } \\
\text { Capital } \mathrm{fm}\end{array}$ & $\begin{array}{c}\text { Outflow } \\
\text { Extern } \mathrm{fm}\end{array}$ & $\begin{array}{c}\text { Net flow } \\
\mathrm{fm}\end{array}$ & $\begin{array}{c}\text { Discount } \\
\text { Factor }\end{array}$ & $\begin{array}{c}\text { Net DCF } \\
\mathrm{fm}\end{array}$ \\
\hline 2004 & 6.50 & 35.00 & & -28.50 & 0.9091 & -25.91 \\
\hline 2005 & 6.50 & & & 6.50 & 0.8264 & 5.37 \\
\hline 2006 & 6.50 & & & 6.50 & 0.7513 & 4.88 \\
\hline 2007 & 6.50 & & & 6.50 & 0.6830 & 4.44 \\
\hline 2008 & 6.50 & & & 6.50 & 0.6209 & 4.04 \\
\hline 2009 & 6.50 & & & 6.50 & 0.5645 & 3.67 \\
\hline 2010 & 6.50 & & & 6.50 & 0.5132 & 3.34 \\
\hline 2011 & 6.50 & & & 6.50 & 0.4665 & 3.03 \\
\hline 2012 & 6.50 & & & 6.50 & 0.4241 & 2.76 \\
\hline 2013 & 6.50 & & & 6.50 & 0.3855 & 2.51 \\
\hline TOTAL & 65.00 & 35.00 & & 30.00 & & 8.12 \\
\hline
\end{tabular}

\section{0}

The study compared the provision of 1000 bed spaces in an extensive villa style development with concentrated high-rise resort development. The students tend to think that villa style development is more sustainable and the IA shows that it provides a much greater private NPV. However, the external costs that are included in CBA show that the high-rise concentrated development generates a greater social NPV. This is largely due to the very great infrastructure cost of providing utility services and access to developments spread all over the island, together with the greater land take, energy consumption and water demand associated with villas each with their own swimming pools and air conditioning systems.

Of particular relevance to sustainability is discounting. There is an argument that intergenerational equity implicit in the resource based view of sustainability demands a discount rate of zero. A valuable discussion of the theoretical basis of discounting can be based on issues of inflation, risk and time preference.

Students can construct their own CBA using CBA builder (see Section 7).

CBA leads naturally into the evaluation of environmental impacts (see Box 4) The potential contribution of CBA to deciding macro policy priorities has been illustrated recently in the Stern Review (Stern, 2006), in which it was the key methodology for assessing the benefits of intervening to reduce carbon emissions and thus to reduce the likelihood of further global warming. 


\section{Teaching a contending perspectives course on economics of the environment}

All of the course structures contained in this chapter are of course simply materials from which to draw. Above, one could choose to teach the courses as laid out, or pick elements to include in one's own introductory or intermediate microeconomics courses. Both of these courses are core to the curriculum, and are ideal if one's goal is to integrate sustainability into the curriculum. However, if one chose instead to create specialist courses, or if the goal was to allow students to build on earlier core courses, a different model is required. The next two sections discuss two possible options: one is a course on economics of the environment; the second (Section 5) is on economics of/for sustainability.

The first is presented again as a set of possibilities. There are a number of ways in which one could teach a course on the economics of the environment. A standard approach is to teach 'environmental economics'. Such a course would emphasise the principles of the left column in Box 6. This draws on literatures called 'environmental economics' and 'natural resource

\section{Box 6: Ecological and environmental perspectives}

\section{Environmental economics}

Orthodox, neo-classical approach (in general), emphasising rationality, optimisation and efficiency.

'Economy-first' approach. Applies economics to the environment.

Efficient allocation of scarce environmental resources.

Predictability of the long run (at least probabilistically)

Microeconomic emphasis

Analysis is value-free: there are no over-riding moral imperatives

Markets are generally efficient and produce socially-optimal economic outcomes. Market and exchange solutions to economic problems are emphasised. Public goods do represent problems.

Externalities emphasised.

Government intervention might be a necessary evil in some cases (e.g. public goods). Proper allocation of private property rights should solve most problems.

\section{Ecological economics}

More affinity with heterodox, non-orthodox economics, emphasising power, change and social nature of the economy

'Ecology-first' approach. Draws on natural sciences.

Scale crucial. Efficiency and distribution also important. Importance of equity.

The long term is inherently uncertain. The long term is paramount. The precautionary principle applies. Macroeconomic or holistic or systemic emphasis Analysis is inevitably value-laden: there can be a moral imperative to protect the environment, other species, etc., as well as a survival imperative.

Markets are social institutions, which might or might not (generally thought not to) produce so-called optimal economic outcomes.

'System' approach makes nothing 'external'. Government is on the whole inevitably necessary to intervene in markets, which will not generally work, and to negotiate international treaties on climate, etc. 
economics', which tend to be constructed on conventional economic principles. As an alternative, or complement, one might teach 'ecological economics', a literature in which the items in the right column of Box 6 are emphasised. Again, there is a choice about to what extent one employed ecological economic principles and concepts. One could integrate them into an essentially conventional course on environmental economics, either extensively or piecemeal. Or, one might choose to teach from the ecological economics perspective. In terms of sustainability, this could be justified if one agreed that ecological economics is the 'science of sustainability' (Costanza et al., 1991).

Many of the concepts in the left-hand column of Box 6 are familiar to most economists, being derived from standard theory. A typical course on environmental economics might look something like the left-hand column. Another variant is to deliver 'natural resource economics' in which both renewable and non-renewable resources are considered. Ecological economics is a somewhat younger branch of the discipline. The focus is more on approaching ecological processes than from an economic perspective. Two names are particularly prominent in ecological economics: Herman Daly and Robert Costanza. They demonstrated the immense value of natural systems by attempting a monetary valuation of them, and the total value they derived dwarfed the value of other inputs into economic systems (Costanza et al., 1991). Daly also proposed a steady-state economy in the sense that it operates so as to avoid further ecosystem degradation but rather enables natural systems to recover (Daly, 1991). There is considerable overlap in the subject matter of ecological and environmental economics. The key difference is one of orientation: environmental economics tends to embrace the neo-classical paradigm as an analysis of the economic system and seeks to incorporate environmental assets and services into that behavioural model. The objective is to maximise economic welfare. Ecological economics gives priority to the health of complex interrelated ecological systems and considers how economic behaviour can be modified to that end.

A third alternative is to teach both 'environmental economics' and 'ecological economics' in debate or, in parallel, i.e. as complementary or contending perspectives. Again, the instructor faces a choice of how to do this. In the course shown below (see Table 2) the contrast between the two views of economics is presented almost immediately.

The course begins by outlining the current world situation. It is hoped that this would stimulate interest. It is important to stress at that point that there are a number of issues to consider. Whilst it is important to bear in mind that there are dissenters to the near-consensual view on anthropogenic climate change, it is unproductive to get stuck on that issue; it is better to move on to questions of biodiversity loss, resource depletion and the like.

After this opening follows the discussion of the two contending (or complementary) perspectives. Again, at this point, the instructor has to choose whether to see the perspectives as arguing over who is correct (contending) or as both providing insights that fit with those of the other (complementary). This choice affects the entire delivery of the course and is particularly acute in its assessment. Students can be asked to consider a problem from both perspectives and consider which one is better, how to use both, or even be invited to supersede each in a novel combination. Whichever of these routes is taken, there is a danger of confusing students; however, these dangers can be reduced if the contrast is introduced early in the process, and if it is reinforced often, particularly in assessment. Thereafter, the course is a series of topics on which each perspective has a bearing to differing degrees.

It is true that much of the early material is from natural science and it would be unreasonable to expect economics instructors to be au fait with many of them.

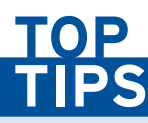

"Using multiple perspectives can be challenging to students. Guide them carefully, but do not push them through the contrasts." For example, most would not have a command of the laws of thermodynamics; however, some rudimentary knowledge of them would be required. The crucial point to get across is of entropy and of how it is necessary to have systems that are open. Similarly, it requires an ecologist to understand fully the nature of ecosystem services; however, the main 


\begin{tabular}{|c|c|}
\hline Topic & Emphases \\
\hline Current state of the world & $\begin{array}{l}\text { Major issues: resource depletion, global warming and climate } \\
\text { change; pollution; combined problem of population growth } \\
\text { and inequality }\end{array}$ \\
\hline Two views on economics & See Box 6 on ecological and environmental economics \\
\hline Ecosystems & $\begin{array}{l}\text { Notions of materials balance; keystone species (Paine, } 1969 \text { is } \\
\text { the seminal piece) }\end{array}$ \\
\hline Thermodynamics & Laws of thermodynamics \\
\hline Sustainability & See Box 1; damage functions, assimilative capacity \\
\hline Growth and the environment & Environmental Kuznets Curve (see Box 7) \\
\hline Externalities and property rights & Optimal level of output and pollution; policies to achieve them \\
\hline Cost benefit analysis & See Box 5 \\
\hline Ecosystem services - valuation & See Box 4 on valuation \\
\hline Sustainability and biodiversity & Quasi-option value see Box 4 \\
\hline Human populations and ecology & Food; agricultural sector; diet \\
\hline Resource use and renewability & $\begin{array}{l}\text { Finite and renewable resource models - MSY (see Box 2); } \\
\text { Hotelling model (see Box } 8 \text { ) }\end{array}$ \\
\hline Trade and pollution & Off-sets; UK exporting ecological/carbon footprint via FDI \\
\hline Climate change & Carbon footprint; the Stern review; impact of climate change \\
\hline Adaptation and resilience & $\begin{array}{l}\text { Carbon capture and storage (CCS) technology; localism; flood } \\
\text { defences; genetically-modified crops }\end{array}$ \\
\hline
\end{tabular}

point of this discussion is to make clear the roles of carbon sinks, etc. and to encourage students to think more broadly about, say, a field than simply its marketable value. Fortunately, standard texts in ecological economics deal with this need by offering definitions of concepts such as damage functions, assimilative capacity and the like.

Many of the other points have already been discussed, and draw on the material elsewhere in the chapter. On many of these there is considerable debate between environmental and ecological economics. For instance on valuation (see Box 4) while ecological economics acknowledges that conventional valuation methods such as WTP and WTA, hedonic pricing, etc. are useful they are more sceptical about their value. Ecological economists are more likely to argue that vital ecosystem services are not amenable to valuation at all, or at least only with considerable scope for error.

The scope for debate continues throughout the course, finishing off with the highly contentious topic of climate change and the controversial Stern Review (2006). The Review is a very useful pedagogical device because it is possibly the most thorough application of techniques of economics of the environment to questions of sustainability (and certainly the most well-known) so provides an excellent vehicle via which to reflect on the rest of the material in the course. Also, the Review is useful because it has been vigorously opposed from both sides of the debate. For example, Nordhaus (2007) has argued that the discount rate assumed by Stern is too low. Dasgupta (2007) is concerned that Stern's discount rate does not take into account sufficiently intragenerational equity. Ackerman (2009) criticises the attempts at valuation within the Review. An obvious capstone to this course would be a debate between groups of students on the Stern Review, in which they are expected to draw on relevant concepts from the course. 


\section{Box 7: The environmental Kuznets curve}

Growth is the most contentious macro-economic objective for sustainability. Ever since the limits to growth hypothesis was put forward in 1972 (Meadows et al., 1972), economic growth has been seen as the enemy of sustainability by most in the green movement. The hypothesis is easier to support now than it was 35 years ago and makes an ideal platform for discussing sustainability at the national level. An opposing view is centred on the environmental Kuznets curve hypothesis, which suggests that as nations become wealthier a point is reached where environmental damage decreases with further economic growth and increases in wealth (Grossman and Krueger, 1991). There are many critiques of this hypothesis. One of the most telling is that the finite resources of the planet constrain the ability of all nations to reach the level of wealth that represents the point of transition from a direct relationship between income growth and environmental damage to an inverse one. The most damning critiques challenge the empirical evidence for the relationship and show that few damage indicators reveal a turning point across those nations for which data are available. Furthermore, the hypothesis does not appear to apply to carbon emissions (Bradford et al., 2005).

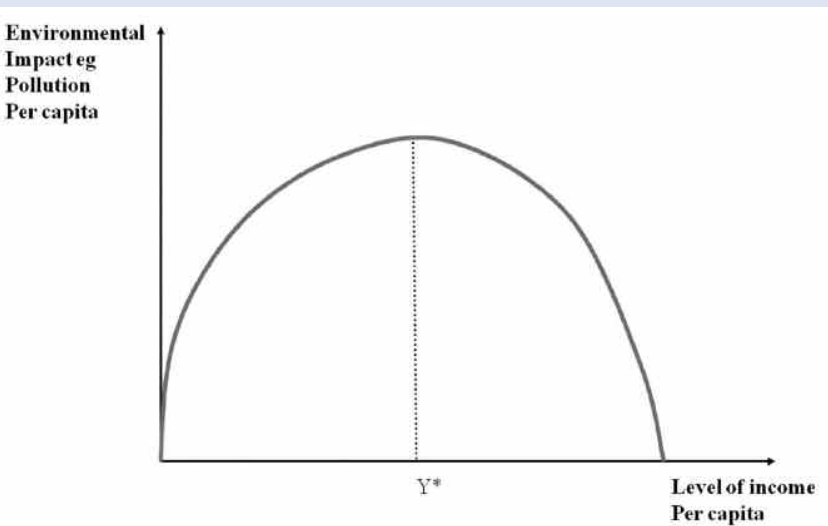

The EKC provides a rich platform for debate. Initially it is appropriate for students to prepare for this by looking at the empirical evidence for the hypothesis. Students should be directed to the results of the original paper by Grossman and Krueger (1995). A recent appraisal of the various critiques that followed over the subsequent 15 years are referred to in Carson (2010). These critiques deal with methodological issues, in terms of data, functional form and analysis. Few of the original pollutants investigated by Grossman and Kruger and shown by them to comply with the hypothesis survive this scrutiny. Students should be able to glean this from the Carson paper and relay their understanding to the class as a whole. However, there are more fundamental issues that students can be guided to in discussion. Even if the EKC held for significant pollutants in one economy, the differing development trajectories of the major global economies are out of phase. Thus at the global level, the rapidly growing BRIC economies and emerging market economies, all at various points on the upward section of the EKC, would more than offset the mature economies which might be at various points on the downward section. Finally, the long lag between the generation of some pollutants and the subsequent ecosystem impact further confuses the picture. 


\section{Teaching an applied course on sustainability economics}

The above course is one on economics of the environment, in which special attention could be put on sustainability. However, one could go a step further and construct a course specifically on sustainability economics. Courses on sustainability economics remain unusual. The course below (Table 3 ) is constructed based on one taught by the authors, combined with some other examples of good practice from around the world.

We feel that in a course on sustainability, starting with the problematic of a sustainable biosphere is unavoidable and desirable. It is essential that students understand the nature of the biosphere, and thence its sustainability, before moving on to consider what economic (and other) systems would be needed to achieve sustainability. One way to approach the question is to lecture about some basic concepts, but then take the main components of the biosphere: soil, marine, hydrosphere, natural forest, wetlands, etc., and divide the class into groups to report back on each part. This could be used as a model for the rest of the course.

One of the consequences of teaching a sustainability course in this way is that students are exposed to economics of complex systems. This exposure may be of benefit in itself. Complexity economics is a relatively young discipline and shares many of its roots and much of its history

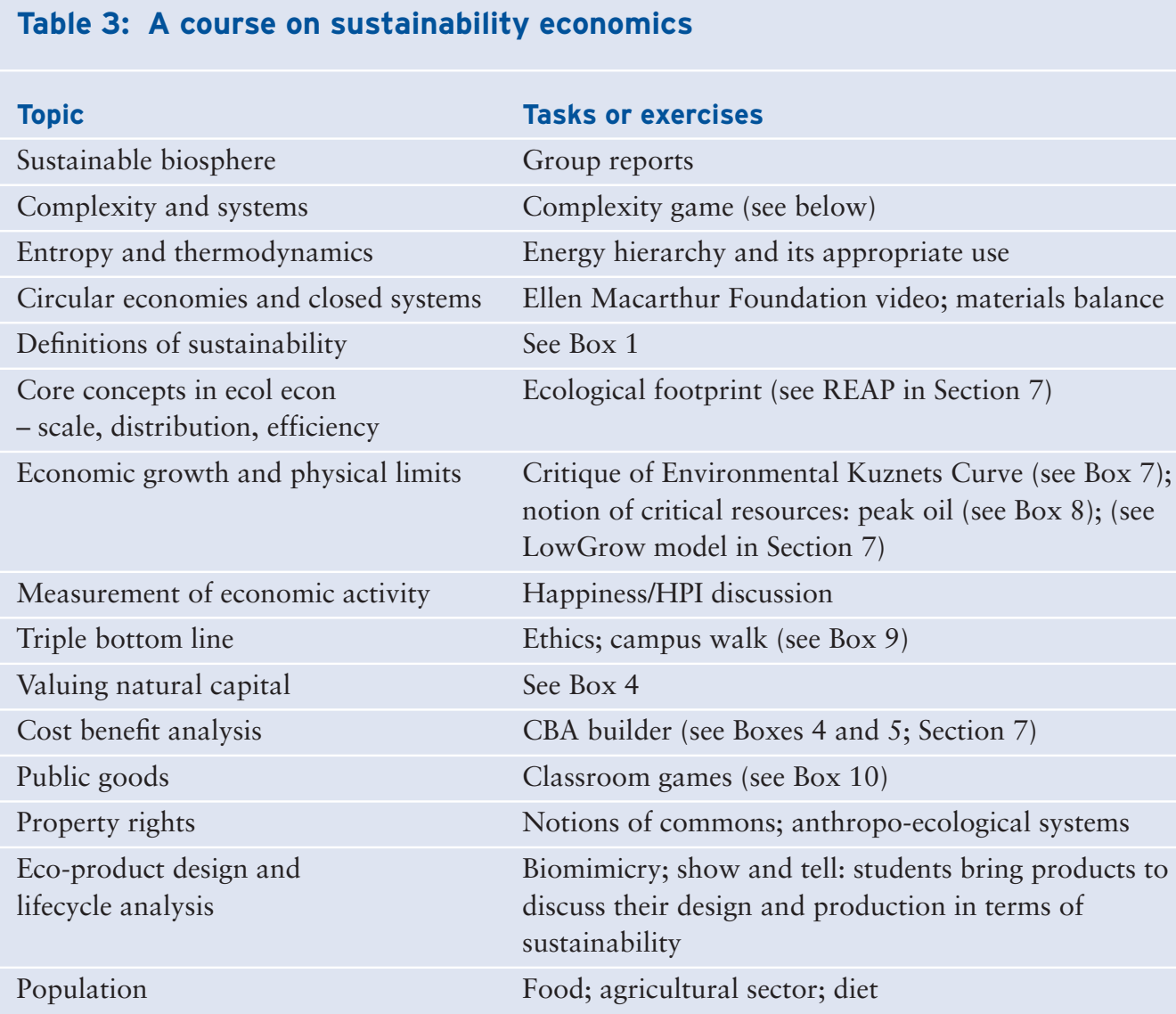

Topic

Sustainable biosphere

Complexity and systems

Entropy and thermodynamics

Circular economies and closed systems

Definitions of sustainability

Core concepts in ecol econ

- scale, distribution, efficiency

Economic growth and physical limits

Measurement of economic activity

Triple bottom line

Valuing natural capital

Cost benefit analysis

Public goods

Property rights

Eco-product design and

lifecycle analysis

Population

\section{Tasks or exercises}

Group reports

Complexity game (see below)

Energy hierarchy and its appropriate use

Ellen Macarthur Foundation video; materials balance

See Box 1

Ecological footprint (see REAP in Section 7)

Critique of Environmental Kuznets Curve (see Box 7); notion of critical resources: peak oil (see Box 8); (see LowGrow model in Section 7)

Happiness/HPI discussion

Ethics; campus walk (see Box 9)

See Box 4

CBA builder (see Boxes 4 and 5; Section 7)

Classroom games (see Box 10)

Notions of commons; anthropo-ecological systems

Biomimicry; show and tell: students bring products to discuss their design and production in terms of sustainability

Food; agricultural sector; diet 
with ecological economics; yet it has a broader application, and has been expounded by significant figures in economics such as Kenneth Arrow and Thomas Sargent. Complexity economics has many implications for both theory and practice. It suggests that even with simple behavioural rules (and hence it has connections with behavioural economics) purposive agents in complex systems can generate unpredictable and potentially explosive outcomes. This has implications for theory: simple rational maximisation becomes less plausible; for methods - agent-based modelling is preferred and the typical mathematics of economics is regarded as inadequate; and for policy - small policy changes can have large and unpredictable outcomes. One way to explore this is via a simple complexity game in which students are divided into small groups; each student receives a card with four rules of behaviour on them (at least one of these might be their objective) to which they must adhere. The object of the game is to show the multiplicity of possible outcomes when faced with simple rules.

By exposing students to these concepts, complexity economics can benefit them but also alarm them. However, arguably in studying sustainability, complexity is essential because it attempts to capture interconnections and systemic effects in ways that even DSGE models do not (see, for example, Colancler et al., 2008). Further, by tapping into modes of thought currently used by governments and other researchers, students are increasing their employability.

\begin{tabular}{l} 
"Introduce students to a \\
delicately balanced \\
ecosystem, so as to \\
understand the complexity of \\
sustainability. Example: a \\
delicately balanced ocean \\
floor ecosystem, whereby \\
bacteria process organic \\
detritus in various ways, \\
some of which lock up carbon \\
and some of which do not, \\
dependent, crucially on the \\
presence of a virus (see The \\
Economist, 2010)." \\
\hline
\end{tabular}

\section{Box 8 : Non-renewable resources}

Resource depletion models

The efficient allocation of resources assumes perfect information is available to assist both producers and consumers in their decision-making. One of the key problems in achieving sustainability is that finite resource costs do not necessarily reflect scarcity. This has been most evident in the case of oil and metals - it is arguable that this failure of the price of these resources to reflect scarcity is due to a combination of a lack of information about remaining reserves and a degree of monopoly power combined with short-termism on the part of certain producers and speculation (Krugman, 2009).

In the case of oil, this has resulted in long periods of relative stability at historically low prices (1985-2006) with shorter periods of extreme volatility (1972-1985 and 2007 to the present). The predictions of economic models of finite resource depletion are at odds with this reality. They assume perfect information and suggest a steadily increasing price path up to the point at which the resource is depleted and an alternative technology takes over (see, for example, Hotelling, 1931, shown graphically below).

The model assumes that exploiters of the resource act to maximise the present value of the future stream of royalties (revenue less extraction costs). This requires that the price path in the top right-hand quadrant reaches the backstop technology price $\mathrm{Pb}$ at the point that the resource is fully depleted. This is shown by going down through the bottom right-hand quadrant to the

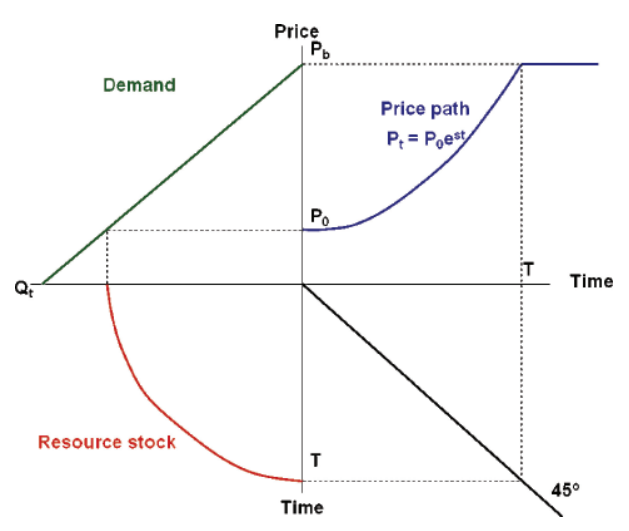


resource stock quadrant, bottom left. The starting price P0 relates through the demand curve to the starting stock position.

It is useful to start a discussion of the actual price path of oil in relation to the model above. Students could be asked to research the historical path of oil prices from, say, 1945, to the present and show this graphically. At first sight this empirical evidence seems at odds with the price path and the class can be asked to try and reconcile the model to reality. After discussion of the actions of OPEC in restricting supply and speculators in increasing demand, the impact of new discoveries of reserves can be introduced as shown below. This illustrates the impact of information.

Information also has an important role in the sustainable harvesting of renewable resources (see Box 2).

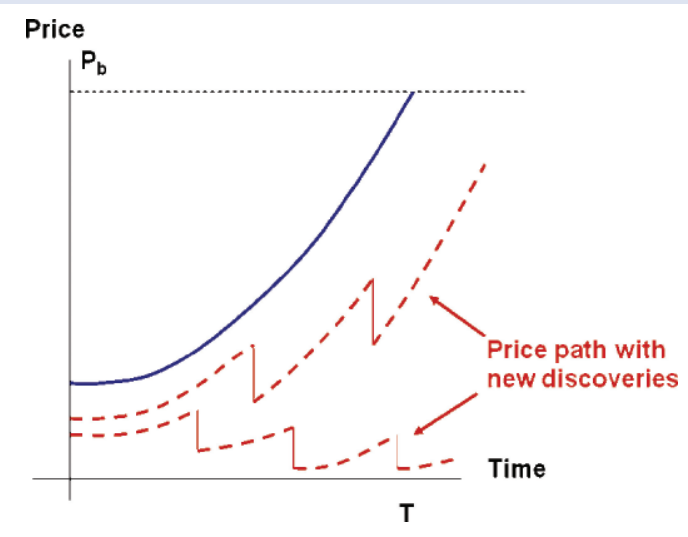

There is increasing evidence that government economists use complexity in their own work, even if they are perhaps unsure how to do so.

The course contains several elements which could be applied to any of the other models above. For instance, the concept of ecological footprint captures the notion of sustainability quite well; and it is empirical and can be evaluated using the REAP software (see Section 7). Under the heading of growth, the macroeconomic consequences of low growth (or even de-growth) could be explored via the LowGrow computer simulation model (Victor, 2008) (see Section 7). A discussion of growth as an objective creates the potential for a discussion of happiness literature, which has much contemporary currency. The literature is varied but includes large econometric analyses so can be a valuable way to explore empirical issues as well as those associated with utility maximising consumers. The issues of valuation and CBA were discussed above, but clearly are important here. A show and tell session, in which students bring in examples of products into class for critical analysis, using life cycle analysis, might be an effective way to discuss that analysis but also asks the students to explore everyday objects from a new perspective.

In a discussion of ethics, following on from definitions of sustainability, is the notion of clashing ethical bases and contesting needs. This clash is captured well by the concept of the Triple Bottom Line (see Section 2.1). One way to explore this concept is via a campus walk, to demonstrate that each part of the university campus has on it competing demands which must be resolved. Obviously each one would be different and would need to be investigated beforehand. 


\section{Box 9: Campus walk}

It is essential that students see concrete examples of sustainable and non-sustainable design and practice. Case studies can be useful in this regard, as can an assessment that requires the students to go out to evaluate actual organisations. A useful place to start is on one's doorstep: the campus. Many educational institutions have made recent efforts to be more sustainable, often through energy efficiency measures which can generate financial savings. So one would expect to be able to find many examples of sustainable buildings and processes on university campuses. Start in the classroom. Ask students to look around and identify sustainable and non-sustainable objects or design features. Students will note double-glazed windows, motion sensors, thermostats and even carbon dioxide sensors, the amount of natural light entering the room, and the number of electrical appliances, for example. Leaving the classroom, students can observe how corridors are lit and heated, whether doors and windows are closed, and how frequently they spot a recycling centre, for example. A campus with some design innovations assists in this task, as students may see - or be invited to see - smart heating and lighting systems, electricity generation or water heating from solar panels, integrated drainage systems, improvised wildflower and wildlife areas, and innovative spaces that are naturally lit and also facilitate social activities that enhance social sustainability. All of these are potential cases for cost benefit analysis.

Pedagogically these campus walks are also valuable. There is a significant element of active learning present. Clearly the tutor must act as a guide, and plan a route that is likely to have items of interest on it. The instructor must also be open to surprise finds and consequently odd questions. The students must be sufficiently knowledgeable to be able to spot relevant features; so it may not be advisable to schedule the campus walk early in the year. However, as part of a PBL approach, students may be directed to a feature of the campus with particular sustainability issues. Instead, or as well, the university or campus itself could be the problem object to be studied. Such an approach allows students to be more engaged with the topic, and with their campus. It may be that an unforeseen consequence of this activity is that students do things on campus that they otherwise would not. If there is flexibility in assessment, these new student activities could themselves become objects for analysis. For example, students could film their own campus walks, perhaps as group activities, and then show them to their peers. 


\section{Box 10: Classroom games}

Classroom games have been identified as a way of engaging students with economic concepts. Some existing Economics Network resources explicitly address sustainability issues. Others can be adapted.

Copestake (2010) discusses a climate change game that can be played in different formats to allow for different levels of economic knowledge and different levels of complexity in the game. The game explores concepts such as public goods and the iterated Prisoner's Dilemma to explore some of the economic issues connected to climate change negotiations and compliance. The game can also enhance students' transferable skills by employing Excel spreadsheets. As always, such games can be adapted to take into account different theoretical frameworks. In this case, the game rests on theoretical presuppositions, such as the simple self-interest of nations. Tutors might wish to explore that presupposition and the consequences of abandoning it. On the same topic, the BBC has designed a climate change game, which could be used to explore the issues around climate change negotiations and compliance.

Sloman (2002) discusses an international trade game in which some countries are natural resource rich and others may have more manufactured capital. That allows for the immediate discussion of types of capital and their substitutability. The purpose of the game is then for each country to engage in trade to its national advantage. The game is designed to allow 'shocks' to occur, so it is an easy adaptation to introduce into the game ecological shocks, perhaps through the forms of resource price spikes, and to investigate their consequences. Guest (2007) discusses a set of games with implications for sustainability, including on public goods, auctions and trading. These latter two are important in a sustainability context because of the growing importance of emissions trading, carbon permits and other market-based carbon reduction schemes.

The Economics Network resources also contain several games that are more general but again have uses in courses on sustainability. Sloman (2009) discusses an expected value game based on the television programme Deal or No Deal. Clearly this game has applications for sustainability, for example in the notion of risk. This can be extended to discuss non-probabilistic risk and the concept important in sustainability of the precautionary principle. Sutcliffe's (2002) press briefing game and Pigott's (2002) journalistic writing assignment are useful in the context of sustainability given its inevitable political dimension and the importance of communicating findings on sustainability effectively to the public.

The paper aeroplane game, discussed by Mearman (2007), has some similarities to the tennis ball game discussed by Guest (2007) and by Hedges (2004). This is a game originally designed to illustrate diminishing marginal returns in production, but is easily adapted to explore aspects of sustainability. The game asks students to make paper aeroplanes in groups in which increasing numbers of students are involved in production. In the basic form of the game, it is expected that marginal productivity would eventually stop increasing. Students can explore how design of the product and of the production process can affect productivity. There are several sustainability angles on this. Students may consider how efficient the process may appear if energy use is taken into account. Students may also debate the extent to which waste is produced in the process. Students could discuss the likely sources of raw materials and the associated sustainability issues. They might also consider product design and the potential for remanufacture and maintenance of the product. One of the principles of cradle-to-cradle production (McDonough and Braungart, 2002) is that the product should be produced where possible from recycled materials, and that there should be no waste from the production process. 


\section{Assessment}

As has been suggested many times already, assessment is crucial in delivering and generating learning of sustainability. A key principle is to use assessment to encourage engagement. This can be achieved by basing it around practical problems and objects around the students. As always, where possible, a variety of assessment methods is desirable, reflecting the multi-faceted nature of sustainability.

Given the interdisciplinary content of the sustainability curriculum, students may be exposed to very unfamiliar concepts. Pop quizzes and short tests (including multiple choice) can provide easy ways to test understanding of these new concepts, and to provide instant feedback to the students on their own learning. The classroom exercises can also provide opportunities for formative assessment. For example, students can be asked to present their ideas on how to achieve economies of scale in the most sustainable ways. They might be asked to write a reflective piece on their walk around their campus. Indeed, the university can be a valuable source of material which to study. As an example, in a module called Sustainable Business we have asked students to engage in coursework that allows them to study anything relevant to sustainability. In this case, almost two thirds of students choose to evaluate a real company or event. Many of those have been studies of what is going on at our university. The university has the advantage of being personally relevant to the students and therefore engaging; and of course it is also convenient, and with some minimal co-operation from university facilities and administrative staff, students can gain access to a wide data set on which to base their analyses.

Other classroom exercises could be part of the strategy for formative assessment. One is that of a guided role-play. Students could be asked to consider a scenario and then take roles of various stakeholders in it. For instance, a planning application may have been made for an incinerator. Students could adopt the perspective of a local resident, a planning officer, a local councillor, an environmental assessment expert, and a representative of a group offering the alternative technology of pyrolisis. This exercise helps develop skills of argumentation and presentation, challenges students to think flexibly, and helps them develop an holistic approach to real-world problems. This exercise could be drawn on subsequently, say in the exam: students would be presented with text of a variety of perspectives and then asked to make an assessment. In the latter case, the exercise clearly forms part of formal assessment, but the former could be formative, and could easily be adapted to employ peer assessment and feedback.

Evaluations of real cases tend to be either on current practices of the company or on the environmental impact (via CBA) of a major event, such as mining, or rock festivals. The key determinant of success on this project is whether the student embraces and applies an analytical framework. Where students go

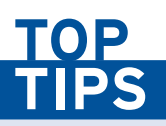

"Use assessment as a tool for engagement: some assessment early on ensures that students master crucial core concepts." wrong is when their projects are too descriptive or lack criticality. The same principles apply when using real-world case studies. In-class cases allow students to explore changes in practice, such as new product lines or production techniques. Again, there are formative assessment opportunities in asking students to present their reflections on these developments. Additionally, in exams students can be presented with such examples and asked to reflect on them. It would also be possible to make some element of the exam open-book assessment, in which students draw on work they have done in class to address either cases they have been working on, or cases new to them. Another option might be to provide a case study to be studied in advance of the examination, with the questions unseen until the exam. In this way, depth of understanding, knowledge and analysis is encouraged. 


\section{Software resources - used as a teaching and assessment tool}

Low Grow is a computer simulation of a macroeconomic model for Canada developed by Victor (2008). The model is an aggregate demand-aggregate supply framework - marrying a typical Keynesian expenditure function with a conventional production function. However, the model has several novel features that make it useful for teaching sustainability. The model has outcomes for conventional macroeconomic variables such as unemployment and growth but in addition tracks greenhouse gas emissions, forestry and poverty. This last element addresses the aspect of sustainability concerned with equity. A further central feature is that, as the name LowGrow suggests, the model examines low growth scenarios.

Students can interact with the computer model by changing key policy variables and witnessing the outcomes. Furthermore the model has several pedagogically advantageous features. The majority of its variables and policy tools are pretty conventional, so students familiar with typical macroeconomics syllabuses can easily adapt to the model. Further, Victor (2008: ch. 10), in conjunction with Victor and Rosenbuth (2007), explains the model in detail. He shows how the model can be represented graphically and in equation form. Victor also discusses the econometric work underlying the calibration of the simulation model. LowGrow therefore has a number of aspects that make it excellent for teaching, at a number of levels.

CBA Builder (Wheatley, 2010) is an Excel-based program designed to allow the user to conduct a cost benefit analysis, together with a sensitivity analysis. The software has several features that make it a useful resource for teaching. It is quite user-friendly and has an accompanying manual containing information on the calculations it performs. Hence it can be used as a tool for reinforcing concepts such as discount rate, net present value and more general concepts such as short and long-run costs. It can therefore be used as an investment appraisal tool. However, by adding in data on externalities CBA Builder can be used for environmental analysis. The sensitivity analysis allows students to understand contingency, which in turn fosters their ability to use judgement and caution in policy decisions. The other benefit for students is in terms of employability: Excel is regarded as a highly useful tool and CBA Builder allows them to develop further their competence in it. CBA Builder has received positive feedback from users.

The Resources and Energy Analysis Programme (REAP) software, developed by the Stockholm Environmental Institute at the University of York, enables students to engage with a number of sustainability issues relating to lifestyle. The current consumption patterns across the UK based on MOSAIC data are used to derive area sustainability profiles in terms of ecological footprint in global hectares, carbon footprint in tonnes and footprints of a range of other pollutants. Geographical areas down to district level can be accessed or new study areas created by aggregating districts. REAP is conceived as a policy instrument whereby local authorities can try out different policy scenarios covering areas such as transport, housing and population growth, and gauge the footprint impact.

A workshop that engages students can be based on their own home district. Overseas students can choose an area they have visited. Initially, students can be asked to find a series of footprints relating to their areas. These can be compared in group discussion and some reasons for differentials suggested. As a second stage, students can enter the scenario mode of the software and try policies which might reduce footprints in their areas. It is a sobering exercise for students to try and evolve policies that bring the ecological footprint down to the sustainable level of 1.8gha. 
Experience with using the software suggests that it is best to start with an introductory group session in a PC lab, defining the metrics and investigating home area profiles. The scenario capability of REAP should be introduced and then students set the footprint reduction exercise to be completed in their own time.

REAP licences for teaching are free and can be obtained through contacts on the website.

The online scenario tool DECC Energy calculator tool is useful to investigate the implications of energy policies. Experience shows that it works best as a seminar exercise where the class as a whole can vote on the various policy decisions. The various implications of strategies can be discussed and the wide range of questions that arise answered. The calculator can be accessed online.

\section{Research}

The University of York reports REAP is used to great effect at undergraduate and postgraduate levels (based on an interview with Anne Owen, Research Associate specialising in Sustainable Consumption and Production, Stockholm Environment Institute, University of York). REAP is a highly sophisticated model that helps policy makers to understand and measure the environmental pressures associated with human consumption. It is aimed at policy makers and can be used at the local, regional and national levels. It generates indicators on:

- Carbon dioxide and greenhouse gas emissions measured in tonnes per capita.

- The ecological footprint required to sustain an area in global hectares per capita.

- The material flows of products and services through an area measured in thousands of tonnes.

REAP has applications in a wide range of policy areas including transport, housing and planning. The program's powerful scenario tool models the impacts of policy changes and facilitates working with alternative futures based on different trends or assumptions.

At York, REAP has been used in teaching on both the BSc and MSc/Diploma Environmental Economics and Environmental Management. At the undergraduate level, it is used to support multi-criteria analysis of sustainable lifestyles while at Masters level, it facilitates the analysis of the impact of lifestyle changes such as reducing food waste and healthy eating. It is important to use a problem-based approach to introducing REAP. Just taking the students through a 'what REAP can do' demonstration does not engage them to the same extent.

There are other versions of REAP available: REAP Petite, which is designed for simulations at the community level; and at the opposite extreme, EUREAPA allows comparative analysis of sustainability indicators at the EU national and regional levels. 


\section{Case studies (in practice)}

This is an unusual area and therefore there are few examples of practice. Plumridge (2010) surveys contemporary provision of areas of the economics curriculum relevant to sustainability. Below we draw extensively from that work to describe relevant case studies.

At the University of Bath, a concern with sustainability is prominent in research and some staff have international reputations in environmental and natural resource economics. There is an interdisciplinary research centre concerned with sustainability, namely the Institute for Sustainable Energy and the Environment. There are two optional modules concerned with sustainability offered at level 3: Environmental Economics, and Natural Energy and Resource Economics. The latter is actively underpinned by research by teaching staff. In the case of these specialist modules, tutorial discussions revealed that, initially, students did not have much familiarity with the concept of sustainability or with areas of economic analysis that were relevant to the concept.

At UWE, Bristol, some economics module leaders are responding to institutional incentives by introducing sustainability issues. A level 2 module, the Business and Economics of Fun and Games, includes applications of economic analysis to the sports and tourism sectors. In the latter, there is consideration of sustainable tourism. At level 3, there has been a long history of teaching environmental economics as an optional module. The recent move of economics into the Bristol Business School resulted in this module being repositioned as Sustainable Business. Some 60 per cent of the content is common to the previous environmental economics module. There is some pressure from students to introduce a module in sustainable business at level 2 . As a response, Good Business, Bad Business and Sustainability (GBBBS) has been designed. Recognising the importance of values in the study of sustainability, GBBBS has a strong emphasis on ethics and corporate social responsibility, as well as introducing foundations of sustainability and frameworks for the economic analysis of it.

The University of Sydney offers a course in the political economy of the environment, which stresses the role of political economic processes in shaping the relation between the economy and the environment. It is an example of a contending perspectives course on the economics of the environment (see Table 3 above). The course uses a mixed assessment strategy. It also deploys a reading kit rather than assigning a textbook, which allows students to read widely and for them to be exposed to canonical readings. Students provide very positive feedback on the course, citing it as engaging, relevant and challenging; and they report that it develops their ability to think about problems from multiple perspectives. Some of the feedback received suggests that there is an important affective dimension to taking such a course.

We can also report that colleagues at Keele University, the University of Missouri at Kansas City, and Flinders University have run successfully modules that stress sustainability. They report positive student feedback, engagement and successful achievement of learning outcomes. 


\section{References/resources}

\section{Resources}

\section{Books}

These books are economics textbooks. They would be suitable at levels 2 and upwards, although for each book, clearly students at level 2 would need more help in understanding the material presented.

Common, M. and Stagl, S. (2005). Ecological Economics: An Introduction, Cambridge: Cambridge University Press.

Costanza, R. (1992). Ecological Economics: the Science and Management of Sustainability, New York: Columbia University Press.

Daly, H. and Farley, J. (2004). Ecological Economics: Principles and Applications, Washington, DC: Island Press (and workbook).

Harris, J. and Goodwin, N. (eds) (2009). 21st century macroeconomics: responding to the climate challenge, Cheltenham: Elgar.

Scott Cato, M. (2008). Green Economics: An introduction to theory, policy and practice, London: Earthscan.

Soderbaum, P. (2008). Understanding sustainability economics: towards pluralism in economics, London: Earthscan.

Spash, C.L. (ed.) (2009). Ecological economics: Critical concepts in the environment, Vols.1-4, London: Routledge.

These books are intended as companion texts; they are not textbooks. They deal with sustainability issues such as energy, change management strategy, and personal consumption decisions. They are suitable at many levels, although some of the technical detail is more suitable for higher level students.

Murray, P. (2011). The Sustainable Self, Oxford: Earthscan.

Stibbe, A. (ed.) (2009). The Handbook of Sustainability Literacy: skills for a changing world, Totnes: Green Books.

Vale, R. and Vale, B. (2008). Time to Eat the Dog? The Real Guide to Sustainable Living, London: Thames and Hudson.

\section{Other cited works}

Ackerman, F. (2009). 'The New Climate Economics: The Stern Review versus its critics', in J. Harris and N. Goodwin (eds) Twenty First Century Macroeconomics: Responding to the Climate Challenge, Cheltenham: Elgar.

Becker, C. (2006). 'The human actor in ecological economics: philosophical approach and research perspectives', Ecological Economics, 60(1): 17-23.

Birkeland, J. (2008). Positive Development: from vicious circles to virtuous cycles through built environment design, London: Earthscan. 
Bradford, D., Fender, R., Shore, S. and Wagner, M. (2005). 'The Environmental Kuznets Curve: Exploring a Fresh Specification', Contributions to Economic Analysis \& Policy, 4(1): Article 5. Available at: http://www.bepress.com/bejeap/contributions/vol4/iss1/art5 Carson, R. (2010) The Environmental Kuznets Curve: Seeking Empirical Regularity and Theoretical Structure, Review of Environmental Economics and Policy 4(1): 3-23. Clark, C. (1990). Mathematical Bioeconomics: The Optimal Management of Renewable Resources, New York: John Wiley \& Sons.

Colander, D., Howitt, P., Kirman, A, . Leijonhufvud, A. and Mehrling, P. (2008). 'Beyond DSGE Models: Towards an Empirically-Based Macroeconomics', paper presented at the AEA meetings, 2008.

Costanza, R., d'Arge, R., de Groot, R., Farber, S., Grasso, M., Hannon, B., Limburg, K., Naeem, S., O’Neill, R. Paruelo, J., Raskin, R., Sutton, P. and van den Belt, M. (1991). 'The Value of the World's Ecosystem Services and Natural Capital', Nature, 387: 253-260.

Council of the European Union (2010). Council Conclusions on Education for Sustainable Development, Brussels.

Daly, H. (1991). Steady-state economics, Washington, DC: Island Press.

Dasgupta, P. (2002). 'Social Capital and Economic Performance: Analytics', E. Ostrom and T. Ahn (eds) Social Capital: A Reader, Cheltenham: Edward Elgar

(2007). 'Comments on the Stern Review's Economics of Climate Change',

National Institute Economic Review, 199, London: Sage.

The Economist (2010). 'Invisible Carbon Pumps', 9 September 2010.

Elkington, J. (1997) Cannibals with Forks: The Triple Bottom Line of 21st Century Business, Oxford, Capstone.

Goodwin, N. (2003). 'Five Kinds of Capital: Useful Concepts for Sustainable

Development', Global Development and Environment Institute, Tufts University

Medford MA 02155, USA, Working paper no. 03-07, available at http://ase.tufts.edu/gdae

Grossman, G. and Krueger, A. B (1991) Environmental impacts of a North American Free Trade Agreement. National Bureau of Economic Research Working Paper 3914, Cambridge MA: NBER.

Hotelling, H. (1931). 'The Economics of Exhaustible Resources', Journal of Political Economy, 39: 137-175.

Jackson, T. (2009). Prosperity without Growth, London: Earthscan.

Krugman, P. (2009). 'Is the threat of speculation a reason to shun cap and trade?' New York Times, 21 July 2009.

McDonough, W. and Braungart, M. (2002). Cradle to Cradle: Rethinking the way we make things, San Francisco: North Point Press.

Meadows, D., Meadows, D., Randers, J. and Behrens, W. (1972). The Limits to Growth, New York: Universe Books.

Mearman, A. (2007). 'Teaching Heterodox Economic Concepts', Handbook for Economics Lecturers, Bristol: Economics Network.

Mearman, A., Shoib, G., Wakeley, T. and Webber, D. (forthcoming). 'Do pluralist curricula make happier, better educated students: a qualitative analysis', International Review of Economics Education, forthcoming.

Nordhaus, W. (2007). 'The Stern Review on the Economics of Climate Change', Journal of Economic Literature, 45(3): 686-702.

Paine, R. (1969). 'A note on Trophic Complexity and Community Stability', The American Naturalist, 103(929): 91-93. 
Perman, R., Ma, Y., McGilvray, J. and Common, M. (2003). Natural Resource and Environmental Economics, Harlow: Pearson.

Plumridge, A. (2010). 'Costing the Earth: The Economics of Sustainability in the Curriculum' in Jones, P., Selby, D. and Sterling, S. (eds) Sustainability Education: Perspectives and Practice across Higher Education, London: Earthscan.

Putnam, R. (2000). Bowling Alone: The Collapse and Revival of American Community, New York: Simon and Schuster.

Stern, N. (2006). The Stern Review: The Economics of Climate Change, London: HM Treasury.

Victor, P. (2008). Managing without Growth: Slower by design, not disaster, Cheltenham: Elgar.

Victor, P. and Rosenbluth, G. (2007). 'Managing without growth', Ecological Economics, 61: 492-504.

WCED (1987). Our Common Future: Report of the Brundtland Commission, Oxford: Oxford University Press. 